Trauma Surgery \& Acute Care Open

\title{
Jejunal duplication cyst in an adult: a rare small bowel complication
}

\author{
Nikhil R Shah, ${ }^{1}$ Byron D Hughes, ${ }^{1}$ Ulises Garza-Serna, ${ }^{2}$ John P Walker ${ }^{1}$
}

'Department of Surgery, University of Texas Medical Branch, Galveston, Texas, USA ${ }^{2}$ Department of Surgery, MercyOne Des Moines, Des Moines, lowa, USA

Correspondence to Dr John PWalker; jopwalke@ utmb.edu
(C) Author(s) (or their employer(s)) 2022. Re-use permitted under CC BY-NC. No commercial re-use. See rights and permissions. Published by BMJ.

\section{To cite: Shah NR,} Hughes BD, Garza-Serna U, et al. Trauma Surg Acute Care Open 2022; 7:e000884.
An ill-appearing woman in her early 50 s presented to the emergency department with a 12-hour history of right-sided abdominal pain associated with chills. Her medical and surgical history were significant for hypertension, a laparoscopic total abdominal hysterectomy, and a laparoscopic cholecystectomy. The patient had not had a previous colonoscopy. She initially attributed the pain to chronic constipation; however, her pain subsequently worsened and became diffuse throughout the day. On physical examination, the patient was afebrile, with normal blood pressure parameters, and slight tachycardia with a pulse of 101 beats per minute. Laboratory values were within normal limits. Her abdomen demonstrated diffuse tenderness to palpation with signs of peritonitis. A CT scan was performed and showed a foci of extraluminal air concerning for a small bowel perforation with an adjacent fluid collection (figure 1).

\section{WHAT WOULD YOU DO?}

A. Exploratory laparotomy

B. Placement of drain by interventional radiology

C. Exploratory laparoscopy

D. Admission for intravenous antibiotic therapy

\section{WHAT WE DID AND WHY}

Given evidence of a contained perforation and hemodynamic stability, exploratory laparoscopy was chosen as the operative management. Our intent was to localize the site of diseased bowel, analyze the underlying etiology for the perforation, and evaluate the characteristics and extent of the adjacent fluid collection. Intraoperatively, a small volume of purulent fluid was noted distal to the ligament of Treitz in the midgut. We then proceeded to examine the bowel in its entirety and a $2.5 \mathrm{~cm}$ cystic appearing mass contiguous with the jejunum, as well as localized gangrenous mesenteric tissue were appreciated. The remainder of the bowel distal to the pathological segment to the terminal ileum appeared grossly normal.

Next, a small midline laparotomy was made in preparation for an extracorporeal anastomosis (figure 2). A $1 \mathrm{~cm}$ perforation on the antimesenteric side of the jejunum was noted. In the standard fashion, the mesentery was scored, and windows were created; the $15 \mathrm{~cm}$ jejunal segment was divided proximally and distally utilizing a GIA-75 stapler. After clamping and ligating the mesenteric vessels, the resected segment was handed off the field and sent to pathology. The extracorporeal anastomosis was performed using a two-layer handsewn technique.
Final pathology demonstrated the cystic mass to be contiguous with the bowel lumen. The mucosa was determined to be both grossly and microscopically similar to the bowel mucosa, consistent with the intraoperative diagnosis of an enteric duplication cyst. These rare congenital malformations are predominantly discovered within the first 2 years of life, with the majority remaining largely asymptomatic. In this hemodynamically stable patient with an acute abdomen secondary to a bowel perforation, we preferred laparoscopic small bowel resection over exploratory laparotomy.

Although historically laparotomy has been the standard of care for an acute abdomen, morbidity associated with this approach has become increasingly well-documented. In weighing the benefits of laparoscopy, the surgical team considered factors such as postoperative narcotic requirement, early walking, length of hospital stay, as well as favorable cosmesis. With evidence of a contained collection and absence of large volume subdiaphragmatic air, it was agreed that laparoscopy could achieve a safe and efficient resection while optimizing the patient's recovery time.

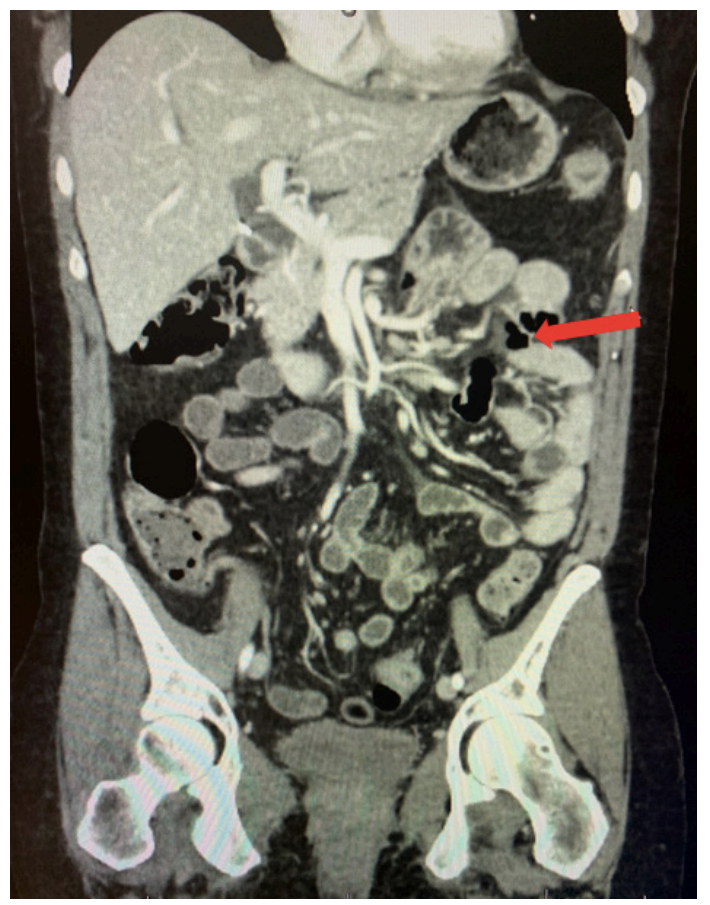

Figure 1 Coronal view of CT abdomen/pelvis demonstrating presence of extraluminal air and fluid, adjacent to the small bowel. 


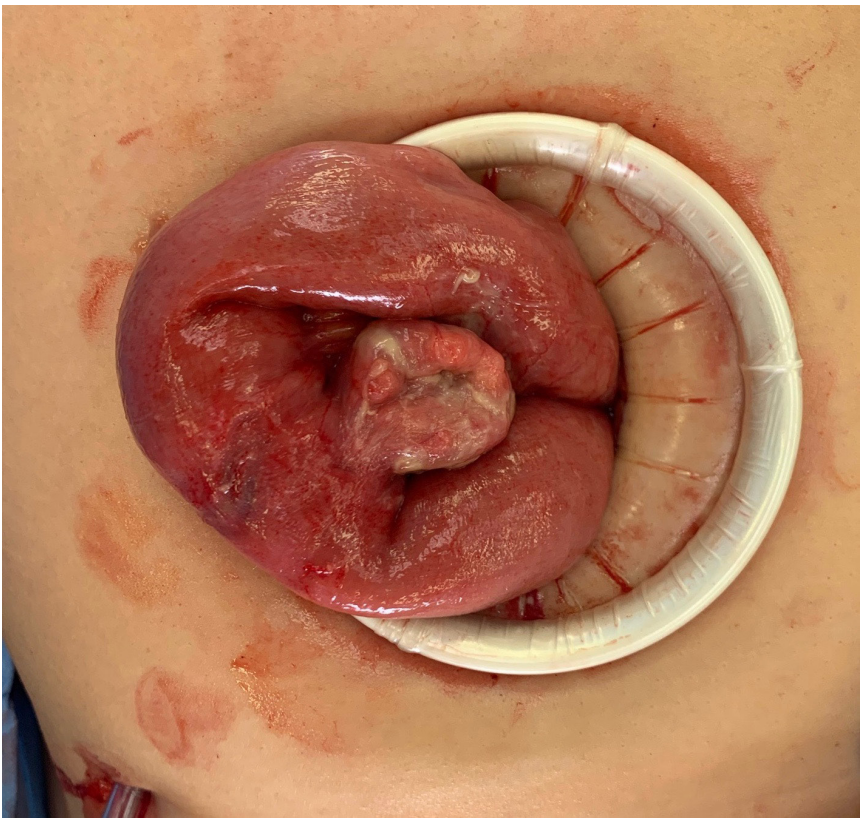

Figure 2 Duplication cyst adherent to segment of jejunum with communication to bowel lumen.
On postoperative day \#1, the patient was fully ambulatory and only required two doses of intravenous narcotics; her pain was otherwise well controlled with multimodal therapy including intravenous and oral anti-inflammatory medications. She tolerated a regular diet on postoperative day \#2 and was discharged on postoperative day \#3 in good condition with return of full bowel function.

Contributors NRS: conceptualization, writing, editing. BDH: conceptualization, writing, editing. UG-S: conceptualization, editing. JPW: editing.

Funding The authors have not declared a specific grant for this research from any funding agency in the public, commercial or not-for-profit sectors.

Competing interests None declared.

Patient consent for publication Consent obtained directly from patient(s)

Ethics approval Approval for this study was not necessary as no experimental intervention or treatment was administered. We describe completely deidentified information and provided the standard of care expected for the presenting symptoms. Participants gave informed consent to participate in the study before taking part.

Provenance and peer review Not commissioned; internally peer reviewed.

Open access This is an open access article distributed in accordance with the Creative Commons Attribution Non Commercial (CC BY-NC 4.0) license, which permits others to distribute, remix, adapt, build upon this work non-commercially, and license their derivative works on different terms, provided the original work is properly cited, appropriate credit is given, any changes made indicated, and the use is non-commercial. See: http://creativecommons.org/licenses/by-nc/4.0/. 